\title{
Gonadal soma-derived factor ( $g s d f$ ), a TGF-beta superfamily gene, induces testis differentiation in the teleost fish Oreochromis niloticus
}

\author{
Hiroyo Kaneko $^{\text {a, b}}$, Shigeho Ijiri ${ }^{\text {a, b, c }}$, Tohru Kobayashi ${ }^{\text {a, d }}$, Hikari Izumic, Yuki Kuramochi', \\ De-Shou Wang ${ }^{a, b}$, Shouta Mizuno ${ }^{c}$, Yoshitaka Nagahama ${ }^{a, b, e}$ \\ ${ }^{a}$ Laboratory of Reproductive Biology, National Institute for Basic Biology, Okazaki 444-8585,
} Japan

${ }^{\mathrm{b}}$ SORST, Japan Science Technology Corporation, Kawaguchi, Saitama 332-0012, Japan

${ }^{c}$ Division of Marine Life Sciences, Graduate School of Fisheries Sciences, Hokkaido University, Hakodate, Hokkaido 041-8611, Japan

${ }^{\mathrm{d}}$ Laboratory of Molecular Developmental Biology, Institute for Environmental Sciences, University of Shizuoka, Shizuoka 422-8526, Japan.

${ }^{\mathrm{e}}$ South Ehime Fisheries Research Center, Ehime University, Matsuyama, Ehime 790-8577, Japan

E-mails. $\quad$ hkaneko@nibb.ac.jp (H. Kaneko), ijiri@fish.hokudai.ac.jp $\quad$ (S. Ijiri), tohruk@u-shizuoka-ken.ac.jp (T. Kobayashi), h-izumi@eis.hokudai.ac.jp (H. Izumi), yuki.kuramochi15@gmail.com (Y. Kuramochi), wdeshou@swu.edu.cn (D.-S. Wang), 
mizuno1003mizuno@yahoo.co.jp (S. Mizuno), nagahama.yoshitaka.mh@ehime-u.ac.jp (Y. Nagahama)

Present address. De-Shou Wang, School of Life Sciences, Southwest University, 400715 Chongqing, People's Republic of China.

Corresponding author. Yoshitaka Nagahama, South Ehime Fisheries Research Center, Ehime University, Bunkyocho 3, Matsuyama, Ehime 790-8577, Japan. TEL: 8189927 8513; FAX: 81 89927 8820; e-mail: nagahama.yoshitaka.mh@ehime-u.ac.jp

Running title Gsdf induces testis differentiation in tilapia.

Abbreviations: transforming growth factor-beta (TGF-beta), gonadal soma-derived factor (gsdf), doublesex/mab-3-related transcription factor-1 (Dmrt1), days post-hatching (dph), quantitative one-step RT-PCR (qRT-PCR), in situ hybridization (ISH) 


\section{ABSTRACT}

The Nile tilapia, Oreochromis niloticus, is a gonochoristic teleost fish with an XX/XY genetic system and is an excellent model for gonadal sex differentiation. In the present study, we screened novel genes that were expressed predominantly in either XY or XX undifferentiated gonads during the critical period for differentiation of gonads into ovaries or testes using microarray screening. We focused on one of the isolated 12 candidate genes, \#9475, which was an ortholog of $g s d f$ (gonadal soma-derived factor), a member of the transforming growth factor-beta superfamily. \#9475/gsdf showed sexual dimorphism in expression in XY gonads before any other testis differentiation-related genes identified in this species thus far. We also overexpressed the \#9475/gsdf gene in XX tilapia, and XX tilapia bearing the \#9475/gsdf gene showed normal testis development, which suggests that \#9475/gsdf plays an important role in male determination and/or differentiation in tilapia.

Keywords $g s d f$, sex differentiation, sex determination, $d m r t 1$, Nile tilapia 


\section{INTRODUCTION}

Many studies have examined sex differentiation/determination systems in vertebrates;

however, several details remain to be elucidated. It has been revealed that $S R Y / s r y$, the sex-linked testis-determining gene, triggers male differentiation in most mammals. In birds, reptiles, amphibians, and fish, extensive efforts have failed to find an ortholog to SRY/sry, suggesting that

$S R Y$ is specific to mammals (Capel, 2000). In teleosts, the sex-determining gene $d m y / d m r t 1 Y b$, whose structure is entirely different from that of $S R Y$, has been identified in the medaka (Oryzias latipes) as a second vertebrate sex-determining gene (Matsuda et al., 2002, 2007, Nanda et al., 2002). In addition, $d m y / d m r t 1 Y b$ is only found in two subspecies among more than 20 related

25 species of medaka (Matsuda et al., 2003). Over the past several years, sex-determining genes have been identified in numerous lower vertebrates, including $d m$ - $W$ in the amphibian Xenopus laevis (Yoshimoto et al., 2008) and gsdfY, amhY, sdY, amhr2 and sox3 in a suite of species of teleost fish, i.e., a medaka-related fish, (Oryzias luzonensis) (Myosho et al., 2012), Patagonian pejerrey (Odontesthes bonariensis) (Hattori et al., 2012), rainbow trout (Onchorhynchus mykiss)

30 (Yano et al., 2012), tiger pufferfish (Takifugu rubripes) (Kamiya et al., 2012), and another medaka-related fish (Oryzias dancena) (Takehara et al., 2014), respectively. Thus, in contrast to many other developmental processes, evolutionary diversity exists in the initial switches of sex 
determination. Conversely, the downstream cascade of genes involved in gonadal sex differentiation has been thought to be relatively conserved among diverse species (Capel, 2000),

35 although differences in downstream regulatory networks between mammals and medaka were recently pointed out (Herpin et al., 2013). Downstream genes such as $d m r t 1$ (doublesex/mab-3-related transcription factor-1) (Adolfi et at., 2015, Guan et al., 2000; Shibata et al., 2002; Smith et al., 1999; Raymond et al., 1998, 1999a), sox9 (Capel, 2000; Kobayashi et al., 2008; Nakamoto et al., 2005; Vidal et al., 2001), amh (anti-Mullerian hormone) (Cutting et al., 2013), wtl (Chen et al., 2013; Takasawa et al., 2014), and foxl2 (Baron et al., 2004; Pailhoux et al., 2002, 2001; Ottolenghi et al., 2005; Wang et al. 2007) have been investigated in many vertebrate species, but the overall gene network and its regulation remain unclear. The Nile tilapia Oreochromis niloticus is a gonochoristic teleost fish that is well characterized as a model for gonadal sex differentiation (Kobayashi and Nagahama, 2009;

45 Nakamura, et al., 1998). Although high temperatures $\left(36^{\circ} \mathrm{C}\right)$ increase the male ratio in some strains of Nile tilapia when applied at the critical thermosensitive period of gonadal differentiation (Baroiller et al., 1995), the strain maintained in our laboratory has displayed a completely stable $\mathrm{XX}-\mathrm{XY}$ genetic sex-determination system over many years when reared at a constant temperature of $26^{\circ} \mathrm{C}$. In this species, sex reversal is easily inducible using sex hormones. Therefore, all-female (XX) or all-male (XY) populations can be obtained through the artificial 
fertilization of eggs from a normal female (XX) with sperm from sex-reversed males (XX) or of normal eggs (XX) with milt from supermales (YY) (Carrasco et al., 1999; Kobayashi et al., 2003, 2002, 2000), respectively. A major locus on the Y chromosome has been shown to control sex determination, but no sex-determining gene has yet been identified in tilapia (Cnaani et al., 2008;

55 Volff et al., 2007). However, the expression patterns of most of the downstream genes involved in gonadal sex differentiation, especially those of foxl2, cyp19ala (P450arom), fshr, hsd17bl, dmrt1, and sox9a, have been investigated (Ijiri et al., 2008; Kobayashi et al., 2008, 2003; Wang et al. 2007; Yan et al., 2012). In light of these studies, the period before/at 5-6 days post-hatching (dph) is critical to the initiation of sex determination/differentiation, in which undifferentiated gonads differentiate into testes or ovaries in tilapia. In the present study, we isolated previously uncharacterized genes that are specifically expressed in the gonads at the initiation of sex determination and differentiation (5-6 dph) in tilapia using cDNA microarray screening. Among the isolated genes, we focused on \#9475/gsdf, which showed much higher expression in XY undifferentiated gonads than in XX gonads. This study aimed to characterize the \#9475/gsdf 65 gene expression pattern and to reveal the role of \#9475/gsdf in gonadal sex differentiation in tilapia. 


\section{MATERIALS AND METHODS}

Nile tilapia were reared in fresh water under constant conditions of temperature $\left(26^{\circ} \mathrm{C}\right)$ and photoperiod (14L: 10D) in indoor tanks (500 L) for over a year until sexually mature. The fish were fed commercial trout pellets ad libitum. Under these conditions, mature females (XX) spawn repeatedly in a cycle of 14-18 days. Eggs were stripped on the spawning day and

75 fertilized by the usual dry method. To obtain all-female (XX) or all-male (XY) populations, sperm stripped from sex-reversed pseudomale (XX) or supermale (YY) fish were used for artificial fertilization, as described elsewhere (Kobayashi et al., 2000). The fertilized eggs were cultured in round-bottom glass tubes $(50 \mathrm{~mL})$, and the eggs were rotated continually by injection of circulating water at $26^{\circ} \mathrm{C}$. The fry hatched at 4 days after fertilization. At 4 to $5 \mathrm{dph}$, the fry

80 were transferred to a 40-L aquarium. At 7 to $8 \mathrm{dph}$, the fry began to feed and were fed daily with commercial food (Otohime B1, Marubeni Nisshin Feed) for fish larvae. All animal husbandry and experimentation was conducted in accordance with our Guide for Care and Use of Laboratory Animals and was approved by the Institutional Committee of Laboratory Animal Experimentation (National Institute for Basic Biology).

\subsection{Microarray screening of cDNAs in $X X$ and $X Y$ undifferentiated gonads}


To isolate the uncharacterized genes that were dominantly expressed in either the XX or $\mathrm{XY}$ gonads at 5-6 dph, we constructed and screened a cDNA microarray. XX-specific cDNA libraries were constructed using XX gonadal cDNA, from which XY gonadal cDNA was

90 subtracted at 5 and 6 dph using a Super SMART PCR cDNA Synthesis Kit and PCR-Select cDNA Subtraction Kit (Clontech). XY-specific cDNA libraries were also constructed in the same manner, using XY gonadal cDNA from which XX gonadal cDNA was subtracted. Approximately 5,500 independent sequences were determined from these subtracted cDNA libraries. Approximately 5,500 additional independent sequences were obtained from EST libraries

95 produced using the SMART cDNA Library Construction Kit (Clontech) from both XX and XY gonads $(5,10$, and $35 \mathrm{dph})$. Approximately 11,000 total independent cDNAs from both the subtracted cDNA and EST libraries were spotted onto glass slides using a GenIII Microarray Spotter (Amersham Biosciences (GE Healthcare)). Microarray screening was conducted using labeled cDNA from XX or XY gonads at 5, 6, and 7 dph using a LabelStar Array Kit and HiLight 100 Array Detection System (Qiagen). Candidate cDNAs expressed predominantly in either XX or $\mathrm{XY}$ gonads in the 5, 6, or $7 \mathrm{dph}$ were selected. All candidate cDNAs were further screened by quantitative RT-PCR (qRT-PCR) using XX and XY gonads at 5, 6, and 7 dph as described in Section 2.5. The terminal sequences of the cDNAs that passed through the qPCR selection were determined using the SMART RACE cDNA Amplification Kit (Clontech). The primers used for 
105 qPCR and RACE are shown in Supplemental Material 1.

\subsection{Phylogenetic analysis}

The predicted mature TGF-beta domains of tilapia \#9475/gsdf; zebrafish, rainbow trout, fugu, stickleback, chub mackerel, and human TGF-beta superfamily members in addition to that of human cystine knot cytokine (human chorionic gonadotropin) were aligned using Molecular Evolutionary Genetics Analysis (MEGA4) software (http://www.megasoftware.net). A phylogenetic tree was constructed using the neighbor-joining method and a bootstrap test with 1000 replicates. Human CG beta was defined as the root. The accession numbers and Ensembl protein IDs for the aligned amino acid sequences are as follows: rainbow trout gsdf,

115 ABF48201.1; rainbow trout gsdf-2, predicted from EST BX080642; medaka gsdf, AB525390; zebrafish gsdf, NP_001108140.1; stickleback gsdf, ENSGACP00000021554; chub mackerel gsdf, ACV32357.1; fugu gsdf, ENSTRUP00000036138; human Inhibin bA, NP_002183.1; human Nodal, NP_060525.3; human GDF1, NP_001483.3; human TGFb1, NP_000651.3; human AMH, NP_000470.2; human GDNF, NP_000505; human CG beta, NP_000728.

\subsection{Tissue distribution analysis by RT-PCR}

Total RNA samples were extracted from the gonadal and somatic tissues (brain, liver, 
pituitary, spleen, gill, head kidney, heart, kidney and muscle) of adult tilapia. First-strand cDNA was synthesized using M-MLV Reverse Transcriptase (Invitrogen) and random hexamer primers.

125 PCR was conducted with the following \#9457/gsdf gene-specific primers:

5'-ACCCGAAGCTGCCGTCTT-3' (forward primer) and 5'-GACTGCTGGGGTTGCAGTATG-3' (reverse primer). PCR was performed with initial denaturing at $96^{\circ} \mathrm{C}$ for $1 \mathrm{~min}$, followed by 30 cycles of $20 \mathrm{~s}$ at $94^{\circ} \mathrm{C}, 20 \mathrm{~s}$ at $60^{\circ} \mathrm{C}$, and $15 \mathrm{~s}$ at $72^{\circ} \mathrm{C}$. cDNA from $\mathrm{XY}$ gonads at $7 \mathrm{dph}$ was used as a positive control (data not shown). cDNA of

$130 \beta$-actin was amplified as an internal control for RT-PCR using the following primers:

5'-GGCATCACACCTTCTACAACGA-3' (forward primer) and 5'-ACGCTCTGTCAGGATCTTCA-3' (reverse primer). The PCR products were electrophoresed on a $2 \%$ agarose gel.

\subsection{RNA extraction and one-step real-time RT-PCR}

Gonads were sampled at 5, 6, 7, 10, 15, 25, 35, and $70 \mathrm{dph}$. At each sampling point, 30 to 50 fry were sacrificed from both sex groups. The fry were dissected, and their gastrointestinal systems and yolks were removed under stereomicroscopy. RNAlater regent (Ambion) was poured on the coelomic epithelium to stabilize the RNA in the gonads, which were then removed using fine forceps. Thirty to fifty gonads were pooled in a tube with RNAlater reagent and stored 
at $-80^{\circ} \mathrm{C}$ until RNA extraction. Ovaries or testes from adult tilapia were also sampled and stored in RNAlater reagent. Sampling was repeated at least three times at each time point. Total RNA was extracted from each pool of samples or adult gonads using a column-based RNA extraction kit (RNeasy Micro Kit; Qiagen,). DNase treatment was also conducted on the column in 145 accordance with the manufacturer's protocol. A 1- $\mu \mathrm{L}$ aliquot of each RNA sample was used for quantification on a NanoDrop spectrometer (NanoDrop Technologies). The quantified RNA samples were used for qRT-PCR using the one-step RT-PCR system. Real-time RT-PCR was conducted on an ABI Prism7000 system (Applied Biosystems). Reactions were performed in 20 $\mu \mathrm{L}$ of solution containing $10 \mathrm{ng}$ of total RNA using a one-step real-time RT-PCR kit in 150 accordance with the manufacturer's instructions (SuperScript III Platinum SYBR Green One-Step qRT-PCR Kit; Invitrogen) according to the method established in previous studies (Ijiri et al., 2008; Yan et al., 2011). The primer sets were designed specifically for quantitative real-time RT-PCR using Primer Express 2.0 software (Applied Biosystems). The forward primer was 5'-GCTACCTGCCGGTGCACT-3', and the reverse primer was

155 5'-AGCCTGGGACTGCTGGG-3' (amplicon size: $103 \mathrm{bp}$ ). The efficiency of the reaction and the R2 of the primers were 0.99 and 0.99 , respectively. Melting curve analysis was performed for each sample to confirm single amplification. The real-time RT-PCR data were expressed as the mean \pm SEM of at least three independent samples. These data were converted to log 10 values 
for all statistical analyses. The data sets for the XX and XY gonads at each time point were

$7 \mathrm{dph}$ were tested through ANOVA with post-hoc tests (Tukey-Kramer). The data sets for the adult ovaries and testes were compared using Student's $t$-test.

\subsection{In situ hybridization}

the trunk, which contained the gonads, was used for sectioning or whole mount. The trunks of the fry, including the gonads, were dissected at 3, 4, 5, 6, 10 and $20 \mathrm{dph}$ and fixed with $4 \%$ paraformaldehyde in PBS (4\% PFA) at $4^{\circ} \mathrm{C}$ overnight. Testes and ovaries were removed from the fry at 40 and $70 \mathrm{dph}$, together with the coelomic epithelium, and fixed with $4 \%$ PFA. After

170 fixation, PFA was replaced with $100 \%$ methanol, and the samples were stored at $-30^{\circ} \mathrm{C}$ for whole-mount in situ hybridization. For section in situ hybridization, the samples were embedded in paraffin, and cross sections were cut at $4 \mu \mathrm{m}$.

A 1055-base pair (bp) cDNA fragment from the 5' end of the \#9475 cDNA was subcloned into the pGEM T-easy vector (Promega). Probes for sense and antisense digoxigenin

175 (DIG)-labeled RNA strands were transcribed in vitro from this plasmid with T7 or SP6 RNA polymerase (Roche Diagnostics) and DIG RNA Labeling Mix at 10X concentration (Roche 
Diagnostics). In situ hybridization was performed as follows. The sections were deparaffinized, hydrated, treated with $10 \mu \mathrm{g} / \mathrm{ml}$ proteinase $\mathrm{K}$ (Wako Pure Chemical Industries) at $37^{\circ} \mathrm{C}$, and then hybridized with sense and antisense DIG-labeled RNA probes $(100 \mathrm{ng} / \mathrm{ml})$ at $60^{\circ} \mathrm{C}$. The

180 hybridization signals were then detected using the Anti-DIG-AP Fab fragment (Roche Diagnostics), and a solution of NBT (Roche Diagnostics) mixed with BCIP (Roche Diagnostics) was used as the chromogen. Whole-mount in situ hybridization was performed as follows. The samples in $100 \%$ methanol were hydrated and subjected to the same procedure used for in situ hybridization. After signal color development, the samples were washed with PBST (PBS with $0.05 \%$ Tween 20 ), and transferred to $25 \%$ and then $50 \%$ glycerol/PBST. The gonads were removed from the trunk, placed on a slide glass, and then covered with cover glass.

\subsection{Production of polyclonal antiserum and immunological detection of \#9475 protein} cDNA encoding \#9475 amino acid residues 39-109 (GenBank Accession No.

190 AB583676.1) was ligated into the $\mathrm{pQE}-30$ vector (Qiagen) with a six-histidine residue at the amino terminus. Polyclonal antiserum for the recombinant protein was generated and the $\operatorname{IgG}$ fraction was used for immunoblotting and immunohistochemistry according to a protocol described elsewhere (Ijiri et al., 2006) with minor modification as follows. Supernatants of testicular and ovarian homogenate (homogenized with $150 \mathrm{mM} \mathrm{NaCl}, 1 \mathrm{mM}$ EDTA, $1 \%$ 
195 Nonidet ${ }^{\mathrm{TM}}$ P-40, $0.2 \mathrm{mM}$ APMSF, $50 \mathrm{mM}$ Tris, $\mathrm{pH}$ 7.5) were subjected to immunoblot analysis.

To evaluate the specificity of the antiserum, pCAGGS containing the ORF of \#9475 (see Section 2.8) was transfected into human embryonic kidney (HEK) 293 cells according to a method described elsewhere (Zhou et al., 2007). Incubation media were collected at 1 and 2 days after the transfection and subjected to immunoblot analysis. Sections ( $5 \mu \mathrm{m}$ thick) from gonads in 7 dph and adult testes and ovaries were subjected to immunohistochemical analyses.

\subsection{Overexpression of the \#9475 gene}

In vivo transgenic overexpression of the \#9475 gene in XX individuals was performed according to the methods of our previous study (Wang et al., 2007). An expression plasmid for

205 \#9475 was produced as follows. Complementary DNA encoding the ORF of \#9475 was amplified by PCR with a primer set introducing the EcoRI and SalI sites, as indicated by the underlined sequences (forward primer 5'-TGTGAATTCACCATGGCCTTTCCA-3' and reverse primer 5'-ACAGTCGACAGCCTACTCCTTGCC-3'). The amplified fragment was digested by EcoRI and SalI and ligated into the multiple cloning site downstream of the cytomegalovirus

210 (CMV) sequence of the pIRES-hrGFP-1a vector (Stratagene). The prepared construct was microinjected into XX fertilized eggs at the one-cell stage. At 11 months after injection, these gonads were subjected to histological examination. Immunohistochemical examination was 
performed in control XX gonad using antibodies against Cyp19a1a according to a previous report (Kobayashi et al., 2003). Over-expression of the \#9475 gene was repeated using a

215 pCAGGS vector that did not contain any reporter gene to exclude the possible influence of GFP on tilapia gonadal differentiation. The ORF of \#9475 was inserted into the XhoI site in the multiple cloning site of the pCAGGS vector (Niwa et al., 1991). The I-SceI meganuclease recognition sequence (TTAGGGATAACAGGGTAATT) was also inserted into the HindIII site of the pCAGGS vector after the polyadenylation signal of the vector itself. The construct was

220 microinjected into XX fertilized eggs with I-SceI meganuclease according to the method previously used for Medaka transgenesis (Thermes et al., 2002). XX fertilized eggs were also given injections of I-SceI meganuclease alone. At 3 months after injection, the gonads were subjected to histological examination.

\section{3. RESULTS}

\subsection{Isolation of predominantly expressed genes in male and female undifferentiated gonads} during the sex-determining period of Nile tilapia

Our previous study indicated that the exact timing of gonadal sex differentiation and development in the $\mathrm{XX}$ and $\mathrm{XY}$ gonads of tilapia is 5-6 dph; this period is critical for the differentiation of undifferentiated gonads into either ovaries or testes (Ijiri et al., 2008). 
To isolate uncharacterized genes that were predominantly expressed in either XX or XY gonads at 5-6 dph, we constructed and analyzed a cDNA microarray. 176 genes were identified by the cDNA microarray screening as candidates for differential expression between the $\mathrm{XX}$ and $\mathrm{XY}$ gonads at 5-7 dph. For example, 35 candidate genes were selected as predominantly expressed genes in XY gonad when compared with XX gonads. In this case, 702 genes were selected from a scatter plot of the signals from $\mathrm{Au}$ (XY gonads) and $\mathrm{Ag}$ (XX gonads), and 71 genes were selected by dye swap hybridization. The 35 common genes that were selected from both scatter plots were used for further selection (Fig. 1A). The 17 genes previously identified to be involved in tilapia gonadal differentiation were not selected by this microarray screening. Among the 176 candidate genes, further screening by qRT-PCR indicated that 10 genes were specifically or predominantly expressed in the $\mathrm{XY}$ gonads, and 2 genes were predominantly expressed in the XX gonads (Fig. 1B). Full-length cDNA sequences of these 12 genes and primer sets used for qRT-PCR are shown in Supplemental Material 1. BLAST analysis indicated similarities as follows: \#786 with desmocollin 2 like, \#3972 with MHC class IA antigen UBA1, \#9475 with 245 gonadal soma-derived factor, \#10053 with MHC class I antigen, and \#6211 with von Willebrand factor type A, EGF and pentraxin domain-containing protein 1. The other 7 genes (\#2081, \#2311, $\# 4742, \# 8050, \# 9224$, \#9439, and \#3523) were not similar to known sequences (Supplemental Material 1). All 12 genes were investigated by in situ hybridization using XX or XY gonads in 
5-10 dph as a preliminary experiment. Only \#9475 showed a distinct signal; the other genes

250 showed faint signals or no signal in the gonads (data not shown). Therefore, in this study, we first focused on \#9475.

The full-length \#9475 gene contains 2100 bp, of which 639 bp compose the ORF. BLAST searching in the DNA Data Bank of Japan indicated that the deduced amino acid sequence of the \#9475 shared $46 \%$ similarity with the gonadal soma-derived growth factor-1

$255(g s d f-1)$ of rainbow trout, a member of the transforming growth factor (TGF)-beta superfamily. Recently, the cDNA of medaka $g s d f$ was cloned (Shibata et al., 2010), and its sequence showed $42 \%$ and $51 \%$ similarity with that of rainbow trout $g s d f-1$ and tilapia \#9475, respectively. The length of \#9475 was consistent with that estimated from the virtual northern blot analysis (data not shown). The ORF encoded a protein containing 213 amino acids with 7 conserved cysteine 260 residues (a.a. 110, 139, 142, 169, 170, 199, and 202) (Fig. 2). We also performed a phylogenic tree analysis for \#9475. As shown in Figure 3, the phylogenic tree analysis revealed that \#9475 belonged to the same branch as the $g s d f$ of other teleosts when aligned with the other members of the TGF-beta superfamily, suggesting that tilapia \#9475 is a member of the $g s d f$ family.

\subsection{Tissue distribution of \#9475/gsdf as determined by RT-PCR}

A tissue distribution analysis using RT-PCR revealed that \#9475/gsdf mRNA was 
expressed specifically in the ovary and testis. PCR amplification of cDNA derived from the brain, liver pituitary, spleen, head kidney, gill, heart, kidney, and muscle did not produce a specific amplicon (192 bp). A 342-bp $\beta$-actin fragment was amplified from all samples (Fig. 4A).

270 Quantitative RT-PCR analysis indicated that the adult testis expressed large amounts of \#9475/gsdf mRNA, whereas the adult ovary expressed small amounts ( $p<0.01)$ (Fig. 4B).

\section{3. \#9475/gsdf mRNA expression in gonads during early development}

We performed quantitative one-step real-time RT-PCR analysis to examine the exact

275 expression patterns of \#9475/gsdf mRNA in the gonads during early development (5-70 dph).

The \#9475/gsdf gene was expressed in the XX and XY gonads at $5 \mathrm{dph}$. The expression level in the XY gonads was higher than that in the XX gonads at 5 dph $(P<0.05)$. Thereafter, the levels in the XY gonads increased rapidly until $10 \mathrm{dph}$ and then increased gradually until $70 \mathrm{dph}$. The \#9475/gsdf mRNA level in the XX gonads increased gradually but was consistently lower than that in the XY gonads throughout the period from 5 to 70 dph (Fig. 5A). Although the early sex differentiation-related gene $d m r t l$ was expressed in the $\mathrm{XY}$ and $\mathrm{XX}$ gonads at $5 \mathrm{dph}$, the expression level of this gene did not differ significantly between the sexes. At 6 dph, dmrt 1 expression was significantly higher in the XY gonads than in the XX gonads $(P<0.01)$ (Fig. $5 B)$. 
sexual dimorphism of \#9475/gsdf mRNA expression in tilapia gonads. As shown in Fig. 6, the number of \#9475/gsdf-positive somatic cells in the XY gonads was much larger than that in the XX gonads (Fig. 6B vs. 6F, 6D vs. 6H). The \#9475/gsdf signals were much higher at $10 \mathrm{dph}$ than at $20 \mathrm{dph}$ (Fig. 6B, D). Next, we performed section in situ hybridization to clarify the localization of \#9475/gsdf expression in the gonads during early development (3 to $70 \mathrm{dph}$ ) (Fig.

7). The \#9475/gsdf mRNA was not detected in either the XX or XY gonads at 3 dph (Fig. 7A, F).

In the XY gonads, \#9475/gsdf mRNA first became apparent at 4 dph (Supplemental Material 2C), then increased rapidly from 4 to $7 \mathrm{dph}(\mathrm{Fig} .7 \mathrm{~B}, \mathrm{C})$. The number of cells positive for \#9475 mRNA in the XY gonads rapidly increased, and the signals became stronger, from 4 dph to 10 295 dph (Fig. 7D). \#9475 mRNA expression then continued to gradually increase until $40 \mathrm{dph}$ (Fig. 7K). In the XX gonads, \#9475/gsdf mRNA first became apparent at $5 \mathrm{dph}$ in an obscure manner and was constantly less prevalent than in the XY gonads (Fig. 7G). After $10 \mathrm{dph}$, the number of cells positive for \#9475 in the XX gonads also increased. However, the signals in the XX gonads were much lower than those in XY gonads (Fig. 7F-J). Positive signals for \#9475/gsdf mRNA 300 were detected only in the somatic cells surrounding the germ cells in both the XX and the XY gonads. In the adult testis, expression was detected in the epithelial cells of the intratesticular efferent duct and the surrounding cells of type-A spermatogonia (Fig. 7L, M). In the adult ovary, 
expression was detected in the granulosa cells of previtellogenic follicles, although the expression level was lower than that in the testis (Fig. 7O, P). In this study, no \#9475/gsdf

305 mRNA was observed in any of the germ cells. No hybridization signal was observed for the sense probe in any of the cells (Supplemental Material 2A).

\section{4. \#9475/gsdf protein expression in gonads}

The anti-\#9475/gsdf antiserum detected a single $32 \mathrm{kDa}$ band among proteins prepared

310 from the tilapia adult testis (Fig. 8a). The antiserum did not react with proteins present in supernatants of the adult ovary (Fig. 8b). The antiserum detected a faint band at approximately $32 \mathrm{kDa}$ with proteins present in the incubation media of HEK293 cells transfected with the expression vector harboring the ORF of \#9475/gsdf at 1 day after transfection (Fig. 8c, lane 1), and the $32 \mathrm{kDa}$ band became stronger on day 2 (Fig. 8c, lane 2). The 32-kDa bands were larger

315 than the calculated Gsdf protein size of $23 \mathrm{kDa}$. The greater detected size might be caused by post-translational modification such as glycosylation. In sections of $\mathrm{XY}$ gonads at $7 \mathrm{dph}$, somatic cells attached to germ cells showed immunostaining (Fig. 8d). The immunoreactivity was not detected in XX gonads at $7 \mathrm{dph}$ (Fig. 8e). In the adult testis, immunoreactive cells presented somatic cells surrounding type-A spermatogonia (Fig. 8h), and epithelial cells of the efferent duct (Fig. 8g). 


\subsection{Overexpression of the \#9475/gsdf gene in XX tilapia}

To clarify the function of $\# 9475 / g s d f$ in gonadal differentiation, we overexpressed \#9475/gsdf with GFP in XX tilapia using a CMV promoter-derived expression vector. At 11

325 months after microinjection, we observed that some of the XX tilapia injected with the overexpression vector had a gonadal structure similar to that of XY individuals (Fig. 9B). These gonads exhibited typical testis structure and complete spermatogenesis, and no ovarian structure or oocytes were observed (Male individuals/XX-TG individuals: 5/12). These testes showed mosaic expression of GFP (Fig. 9B, inset) in the same manner seen in our earlier study (Wang et

330 al., 2007). To reconfirm the role of $\# 9475 / g s d f$ in tilapia gonadal differentiation, a different type of vector containing the AG promoter for overexpression of \#9574/gsdf lacking GFP was also introduced into XX fertilized eggs. At 3 months, two of 10 tilapia (XX-TG) had developing testis including development of type A spermatogonia to sperm. This histological feature was the same as that of the normally developing testis of control XY tilapia at three months (Data not

335 shown). The other eight XX-TG tilapia had developing ovaries including perinucleolus oocytes, which represented the same developing stage observed for normal XX tilapia ovaries. All control $\mathrm{XX}$ tilapia and XX tilapia receiving I-SceI meganuclease injection developed normal ovaries (Fig.9A, C). 


\section{DISCUSSION}

\subsection{Identification of predominantly expressed genes in XX or XY gonads}

In the present study, cDNA microarray screening was conducted using $\mathrm{XX}$ and $\mathrm{XY}$

gonads in the early period when differential gene expression occurs between them. Within 5-7

dph, foxl2, cyp19ala, and dmrtl expression begin to increase dependent on the sex. However,

345 these three genes were not selected by the microarray because the intensity of the signal

difference of these genes between XX and XY samples was under 2.0-fold, which was the

threshold employed in this screening. This result indicates a limitation of the cDNA microarray

with regard to the sensitivity to detect small differences in mRNA levels. Even though the three

known genes were not selected, this screening identified 10 and 2 genes that are predominantly

350 expressed in XY and XX gonads, respectively. Among these genes, only \#9475 gene showed

distinct expression by preliminary in situ hybridization (ISH) analyses comparing XX and XY

gonads at 8-10 dph. Therefore, we focused on \#9475 in this study. Among the other genes, two

genes, \#3972 and \#10053, have homology with major histocompatibility complex (MHC) class I,

which is known to play a role in presenting peptide antigens to T cell receptors and is also

355 involved in self-recognition. This gene exists as multiple copies, and the class I genes are highly

polymorphic (Sean et al., 2014). Considering the diversity of the MHC class I genes, the 
detection of specific expression of \#3972 and \#10053 genes in the XY gonads may have resulted from a difference between the YY strains and XX strains, but not from a difference of sex. The \#786 gene had weak homology with desmocollin, which is involved in cell adhesion (Garrod et al., 2002). The other 6 genes predominantly expressed in XY gonads did not show homology with known molecules. Of the 2 genes that showed higher expression in XX gonads, \#6211 has homology with von Willebrand factor, a blood glycoprotein required for hemostasis (Sadler, 1998). The other gene, \#3523 did not match with known sequences. The physiological importance of these genes other than \#9475 remains unknown; however, the lack of detection by ISH in gonads may indicate a lack of involvement in gonadal differentiation.

\section{2. \#9475 is an ortholog of gsdf}

A comparative analysis of the deduced amino acid sequences revealed that \#9475 is most similar to rainbow trout $g s d f-1$ and medaka $g s d f$, a cDNA that encodes a unique member of the TGF-beta superfamily found only in teleost fish (Sawatari et al., 2007; Shibata et al., 2010; Gautier et al., 2011). This may suggest that Gsdf has a distinct role only in teleost fish species. TGF-beta members commonly have seven conserved cysteine residues, six of which (the first through third and fifth through seventh) form a cysteine knot motif, with the fourth cysteine involved in interchain disulfide bonds (Daopin et al., 1992; Kingsley, 1994). Although the gsdf-1 
375 of rainbow trout lacks the seventh characteristic cysteine, \#9475 has seven cysteine residues in keeping with other TGF-beta superfamily members, including the predicted Gsdf of other fish species (Fig. 2). In the rainbow trout, another $g s d f$ form was identified, termed $g s d f-2$. The trout Gsdf-2 contained the seventh cysteine residue; therefore, only trout Gsdf-1 was lacking the seventh cysteine. The phylogenetic tree analysis also suggested that \#9475 is a member of the gsdf family that only exists in fish species (Fig. 3). These data strongly suggest that \#9475 is an ortholog of the $g s d f$ gene in the Nile tilapia.

\subsection{Gsdf is dominantly expressed in XY gonad}

RT-PCR analysis revealed that tilapia $g s d f$ mRNA expression was limited to the ovary and testis, although the testicular expression was much higher than the ovarian expression. This result was consistent with the observations in medaka (Shibata et al., 2010) and rainbow trout (Sawatari et al., 2007). This distinct gonad expression pattern in these three fish species suggests that Gsdf plays a particular role in gonadal development.

In the present study, ISH analysis demonstrated that $g s d f$ mRNA expression began at 4

390 dph in the undifferentiated gonads of XY fry only. The distinct expression of $g s d f$ mRNA in the XY gonads was obvious because the in situ signal intensity rapidly increased from 4 to $10 \mathrm{dph}$; in contrast, the mRNA signals were consistently obscure and maintained at low levels in XX 
gonads until $20 \mathrm{dph}$. This distinct difference in $g s d f$ mRNA expression between $\mathrm{XY}$ and $\mathrm{XX}$ undifferentiated gonads observed by ISH was not reflected in qRT-PCR results at $5 \mathrm{dph}$, although

395 a significantly higher level of $g s d f$ mRNA expression was detected in XY gonads compared with XX gonads $(p<0.05)$.

The differences in mRNA expression detected by qRT-PCR became obvious at $6 \mathrm{dph}(p$ $<0.01)$. Although quantitative data were not obtained at $4 \mathrm{dph}$ because we could not collect a sufficient number of gonads for RNA extraction, it was suggested that $g s d f$ mRNA was expressed after $4 \mathrm{dph}$ and up-regulated in XY gonads at least after $5 \mathrm{dph}$.

The morphological sexual differences in tilapia gonads have previously been reported in detail (Kobayashi and Nagahama, 2009). The first morphological change, a difference in germ cell number between the $\mathrm{XX}$ and $\mathrm{XY}$ gonads, occurs after 9 dph with an increase in the size of XX gonads, whereas the germ cell number does not change until 14 dph in the XY gonads 405 (Kobayashi et al., 2008). Under light microscopy, gonadal sex differentiation appeared at 23-26 dph with the formation of ovarian cavity in the XX gonad or the efferent duct in the XY gonad (Nakamura et al., 1998). This evidence indicates that $g s d f$ mRNA is expressed much earlier than the appearance of morphological sex differences.

In trout, gene knockdown of $g s d f-1$ by inhibition of translation resulted in suppressed 410 primordial germ cell (PGC) proliferation (Sawatari et al., 2007). The suggested role of trout 
Gsdf-1 on PGC proliferation seems to contradict with the lack of change in germ cell number until $14 \mathrm{dph}$, whereas in the present study, $g s d f$ expression increased rapidly during this period in the tilapia XY gonad. In tilapia, the predominant expression of $g s d f$ in XY undifferentiated gonads may play a different role, e.g., maintaining the quiescence of the germ cells or playing 415 roles other than germ cell proliferation.

Our previous study demonstrated that $d m r t 1$ mRNA expression began to increase after 6 dph in XY gonads, and no difference in mRNA levels was observed between XY and XX gonads at 5 dph based on qRT-PCR analyses (Ijiri et al., 2008). This result was confirmed in the present study. Furthermore, our previous study based on ISH demonstrated that $d m r t 1 \mathrm{mRNA}$ was first detected in XY gonads at $6 \mathrm{dph}$ and not detected in XX gonads (Kobayashi et al., 2008). The results obtained from both qRT-PCR and ISH in the present study indicate that $g s d f$ mRNA expression in XY gonads precedes that of dmrtl. Dmrtl is localized in the germ cell-surrounding cells of the morphologically undifferentiated gonad, i.e., in the pre-Sertoli cells (Kobayashi et al., 2008). The $g s d f$ mRNA and protein signals in XY undifferentiated gonads were also detected 425 only in somatic cells surrounding the germ cells. The cells that expressed $d m r t 1$ corresponded to those that expressed $g s d f$ in the undifferentiated gonads. In the adult testis, $g s d f$ mRNA and protein signals were detected in somatic cells adjacent to type-A spermatogonia distributed in the peripheral area of the testis and, in addition, in the epithelial cells of the intratesticular efferent 
duct, where germ cells were not exist. Additionally, dmrtl signals were also detected in the inner area of the testis, at Sertoli cells and the medullary cell mass neighboring the Sertoli cells, which developed into intratesticular efferent duct. In adult testis, dmrtl signals were detected in Sertoli cells for all spermatogenic stages, in addition to epithelial cells of the intratesticular efferent duct (Kobayashi et al., 2008). These observations suggest that not all dmrtl-positive cells in the adult testis express $g s d f$.

not detected (Kobayashi et al., 2008). The detection of $g s d f$ mRNA by ISH in granulosa cells surrounding pre-vitellogenic oocytes in earlier developmental stages was also reported by medaka (Shibata et al., 2010). In coho salmon, the $g s d f$ mRNA level increased in the ovaries from the perinucleus stage to the cortical alveolus stage (Luckenbach et al., 2008). Gsdf

440 expression in ovary thus seems to be common to least these three fish species; however, the physiological importance in the ovary will not be clear until a $g s d f$ knock-out analysis in the XX fish is conducted.

\subsection{Gsdf induces testis-differentiating in the tilapia}


appears to be involved in a certain type of XY sex reversal in humans (Bennett et al., 1993; Flejter et al., 1998; Raymond et al., 1999b; Veitia et al., 2001). In chickens, Dmrtl was mapped to the $\mathrm{Z}$ chromosome (Nanda et al., 2000, 1999). mRNA expression of Dmrtl was also found to occur almost exclusively in the chicken testis during gonadal differentiation, and aromatase inhibitor-treated ZW embryos showed female-to-male sex reversal accompanied by Dmrtl expression in medullary cells (Smith et al., 2003, 1999). A recent study in chickens lends additional support to this hypothesis, as ZZ chickens in which Dmrtl was knocked down by RNA interference showed partial sex reversal (Smith et al., 2009). Additionally, Dmrtl is 455 expressed in the germ cell-surrounding cells and intratesticular efferent ducts after testicular differentiation in medaka, a teleost fish, similarly to its expression in tilapia (Kobayashi et al., 2008 , 2004). However, the sex-determining gene $d m y / d m r t 1 Y b$, a $d m r t 1$ paralog, showed the same localization as $d m r t 1$ prior to sex differentiation (Kobayashi et al., 2008; Matsuda et al., 2007, 2002). Recently, a DNA-binding domain mutant of dmrtl in medaka was shown to cause ovarian differentiation in $\mathrm{XY}$ individuals, suggesting that $d m r t 1$ is required for testis differentiation after $d m y$ sex determination (Masuyama et al., 2012). In the present study, the tilapia $g s d f$ mRNA was dominantly detected in the male gonads in advance of dmrtl detection, and both $g s d f$ and dmrtl were localized specifically in germ cell-surrounding cells in morphologically undifferentiated gonads. In medaka, the expression profiles of sex 
$d m y / d m r t 1 Y b$ during sex determination, but it is expressed earlier than $d m r t 1$ in the Sertoli cell lineage (Kikuchi and Hamaguchi, 2013; Myosho et al., 2012; Shibata et al., 2010; Takehana et al., 2014). The order of expression of $g s d f$ and $d m r t 1$ appeared to be consistent in tilapia and medaka. In the tilapia, upregulation of other genes involving testis differentiation, such as anti-Mullerian hormone (after $15 \mathrm{dph}$ ) and sox9 (after $35 \mathrm{dph}$ ) were delayed far behind $g s d f(5 \mathrm{dph})$ and $d m r t 1$ (6 dph) upregulation in XY gonads (Ijiri et al., 2008), suggesting important roles of $g s d f$ and $d m r t l$ as initial switches to promote testis differentiation.

To determine whether tilapia $g s d f$ plays an important role in testis differentiation, a gain-of-function analysis was conducted in XX tilapia using two different types of

475 overexpression vector. The CMV promoter-derived $g s d f$-GFP clearly induced testis differentiation in $42 \%$ of XX tilapia and led to complete spermatogenesis at nine months post hatching. Furthermore, CAG promoter-derived $g s d f$ also induced testis differentiation in $20 \%$ of XX tilapia at three months. This result ruled out the possibility that testis differentiation was induced by the CMV promoter itself or the GFP protein. In the two experiments, not all XX tilapia injected with the overexpression vectors developed testes, and the tilapia that did not develop testes developed histologically normal ovaries, possibly because of the efficiency of transgenesis as the F0 population was used for analysis. An important question that remains is 
whether the F1-XX population harboring the $g s d f$ overexpression vector completely

differentiates into males or not. In our experimental strain, all XX tilapia develop ovaries.

485 Therefore, the appearance of testis in the XX tilapia did not result from other factors such as

environmental factors or stress. These results for two types of overexpression vector containing different promoters strengthen the conclusion that $g s d f$ itself plays a role in the induction of testicular differentiation in XX tilapia, as $g s d f$ expression was sufficient to induce the entire testis differentiation pathway in XX tilapia. Gsdf is thus likely induced by a hitherto unknown sex-determining gene during physiological development of XY tilapia. To definitively conclude that Gsdf is a necessary factor for induction of testis differentiation in XY tilapia, a loss-of-function analysis is necessary. We injected an engineered peptide nucleic acid (GripNA; Active Motif) designed according to the translation initiation position of tilapia $g s d f$ mRNA into XY fertilized eggs to inhibit the translation of $g s d f$. These injected XY tilapia showed ovarian 495 differentiation, although the differentiation was extensively delayed compared with that of normal XX tilapia (data not shown). This finding may indicate that the suppression of gsdf function by the GripNA (the inhibitory effect may continue at most two weeks after injection) was not sufficient to inhibit testicular differentiation in XY tilapia. A knock-out analysis for the gsdf gene must be conducted to provide a conclusive answer to this question. In O. luzonensis, a subspecies of medaka that lacks $d m y / d m r t 1 Y b$ (Kondo et al., 2004; Matsuda et al., 2003), gsdfY 
(gonadal soma-derived factor on the Y chromosome) was recently identified as a sex-determining gene (Myosho et al., 2012). Further functional analysis indicated that a transgene with a region including the $g s d f Y$ genomic fragment in $\mathrm{XX} O$. luzonensis and $O$. latipes was sufficient to produce fertile males, although the effects of the overexpression of the medaka $g s d f$ open reading frame itself in XX $O$. latipes remains unclear. The present study is the first to report that overexpression of $g s d f$ itself is sufficient to induce testis differentiation. Together with the results in tilapia in the present study, this evidence indicates that $g s d f$ expression induces complete testis differentiation and plays an important role in the testis differentiation pathway.

\subsection{Conclusions and perspectives}

In conclusion, this study demonstrated that $g s d f$ is distinctly and predominantly expressed in XY undifferentiated gonads before any other testis-differentiation-related gene identified thus far in the Nile tilapia. This gene is also sufficient to induce the male sex

515 differentiation pathway in the XX gonads of tilapia. As the relationship between gsdf and dmrt1 remains unclear and no sex-determining gene has yet been identified in tilapia, further studies are necessary to illustrate the initiation mechanism of testis differentiation in relation to the regulatory mechanisms of $g s d f$ and $d m r t 1$ expression in $\mathrm{XY}$ gonads. 


\section{ACKNOWLEDGEMENT}

We thank Dr. Masaru Matsuda, Dr. Kataaki Okubo, Dr. Lin-Yan Zhou and laboratory members of Reproductive Biology, National Institute for Basic Biology for technical help and animal husbandry. This study was partly supported by SORST, JST (Japan Science and Technology Corporation), KAKENHI 24370028 and KAKENHI 26292109.

\section{REFERENCES}

Adolfi, M.C., Carreira, A.C., Jesus, L.W., Bogerd, J., Funes, R.M., Schartl, M., Sogayar, M.C., Borella, M.I., 2015. Molecular cloning and expression analysis of dmrt1 and sox 9 during gonad development and male reproductive cycle in the lambari fish, Astyanax altiparanae. Reprod. Biol. Endocrinol. 13:2.

Baroiller, J.F., Chourrout, D., Fostier, A., Jalabert, B., 1995. Temperature and sex chromosomes govern sex ratios of the mouthbrooding Cichlid fish Oreochromis niloticus. J. Exp. Zool. $273,216-223$.

Baron, D., Cocquet, J., Xia, X., Fellous, M., Guiguen, Y., Veitia, R.A., 2004. An evolutionary and functional analysis of FoxL2 in rainbow trout gonad differentiation. J. Mol. Endocrinol. 33, 705-715.

Barrionuevo, F., Bagheri-Fam, S., Klattig, J., Kist, R., Taketo, M.M., Englert, C., Scherer, G., 2006. Homozygous inactivation of Sox9 causes complete XY sex reversal in mice. Biol. 
Reprod. 74, 195-201.

20 Bennett, C.P., Docherty, Z., Robb, S.A., Ramani, P., Hawkins, J.R., Grant, D., 1993. Deletion 9p and sex reversal. J. Med. Genet. 518-520.

Capel, B., 2000. The battle of the sexes. Mech. Dev. 92, 89-103.

Carrasco, L.A., Penman, D.J., Villalobos, S.A., Bromage, N., 1999. The effects of oral administration with 17 alpha-methyltestosterone on chromosomal synapsis in Oreochromis

$25 \quad$ niloticus (Pisces, Cichlidae). Mutat. Res. 430, 87-98.

Chen, S.R., Chen, M., Wang, X.N., Zhang, J., Wen, Q., Ji, S.Y., Zheng, Q.S., Gao, F., Liu, Y.X., 2013. The Wilms tumor gene, Wt1, maintains testicular cord integrity by regulating the expression of Col4a1 and Col4a2. Biol. Reprod. 88, 56: 1-10.

Cnaani, A., Lee, B.Y., Zilberman, N., Ozouf-Costaz, C., Hulata, G., Ron, M., D'Hont, A., Baroiller, J.F., D'Cotta, H., Penman, D.J., Tomasino, E., Coutanceau, J.P., Pepey, E., Shirak, A., Kocher, T.D., 2008. Genetics of sex determination in tilapiine species. Sex. Dev. 2, 43-54.

Cutting, A., Chue, J., Smith, C.A., 2013. Just how conserved is vertebrate sex determination? Dev. Dyn. 242, 380-387.

35 Daopin, S., Piez, K.A., Ogawa, Y., Davies, D.R., 1992. Crystal structure of transforming growth factor-beta 2: an unusual fold for the superfamily. Science 257, 369-373. 
Flejter, W.L., Fergestad, J., Gorski, J., Varvill, T., Chandrasekharappa, S., 1998. A gene involved in XY sex reversal is located on chromosome 9, distal to marker D9S1779. Am. J. Hum. Genet. 63, 794-802.

40 Garrod, D.R., Merritt, A.J., Nie, Z.X., 2002. Desmosomal adhesion: structural basis, molecular mechanism and regulation (Review). Mol. Membr. Biol. 19, 81-94.

Gautier, A., Gac, F.L., Lareyre, J., 2011. The gsdf gene locus harbors evolutionary conserved and clustered genes preferentially expressed in fish previtellogenic oocytes. Gene 472, 7-17.

Guan, G., Kobayashi, T., Nagahama, Y., 2000. Sexually dimorphic expression of two types of DM (Doublesex/Mab-3)-domain genes in a teleost fish, the Tilapia (Oreochromis niloticus).

Biochem. Biophys. Res. Commun. 272, 662-666.

Hattori, R.S., Murai, Y., Oura, M., Masuda, S., Majhi, S.K., Sakamoto, T., Fernandino, J.I., Somoza, G.M., Yokota, M., Strüssmann, C.A., 2012. A Y-linked anti-Müllerian hormone duplication takes over a critical role in sex determination. Proc. Natl. Acad. of Sci. USA 109, 2955-2959.

Herpin, A., Adolfi, M.C., Nicol, B., Hinzmann, M., Schmidt, C., Klughammer, J., Engel, M., Tanaka, M., Guiguen, Y., Schartl, M., 2013. Divergent expression regulation of gonad development genes in medaka shows incomplete conservation of the downstream regulatory network of vertebrate sex determination. Mol. Biol. Evol. 30, 2328-2346. 
55 Ijiri, S., Takei, N., Kazeto, Y., Todo, T., Adachi, S., Yamauchi, K., 2006. Changes in localization of cytochrome P450 cholesterole side-chain cleavage (P450scc) in Japanese eel testis and ovary during gonadal development. Gen. Comp. Endocrinol. 145, 75-83.

Ijiri, S., Kaneko, H., Kobayashi, T., Wang, D.S., Sakai, F., Paul-Prasanth, B., Nakamura, M., Nagahama, Y., 2008. Sexual dimorphic expression of genes in gonads during early 60 differentiation of a teleost fish, the Nile tilapia Oreochromis niloticus. Biol. Reprod. 78, 333-341.

Kamiya, T, Kai, W, Tasumi, S, Oka, A, Matsunaga, T, Mizuno, N, Fujita, M, Suetake, H, Suzuki, S, Hosoya, S, Tohari, S, Brenner, S, Miyadai, T, Venkatesh, B, Suzuki, Y, Kikuchi, K., 2012. A trans-species missense SNP in Amhr2 is associated with sex determination in the tiger pufferfish, Takifugu rubripes (fugu). PLoS Genet. 8, e1002798.

Kikuchi, K., Hamaguchi, S., 2013. Novel sex-determining genes in fish and sex chromosome evolution. Dev. Dyn. 242, 339-353.

Kingsley, D.M., 1994. The TGF-beta superfamily - new members, new receptors, and new genetic tests of function in different organisms. Genes Dev. 8, 133-146.

70 Kobayashi, T., Nagahama, Y., 2009. Molecular aspects of gonadal differentiation in a teleost fish, the Nile tilapia. Sex. Dev. 3, 108-117.

Kobayashi, T., Kajiura-Kobayashi, H., Nagahama, Y., 2000. Differential expression of vasa 
homologue gene in the germ cells during oogenesis and spermatogenesis in a teleost fish, tilapia, Oreochromis niloticus. Mech. Dev. 99, 139-142.

75 Kobayashi, T., Kajiura-Kobayashi, H., Nagahama, Y., 2002. Two isoforms of vasa homologs in a teleost fish: their differential expression during germ cell differentiation. Mech. Dev. 111, $167-171$.

Kobayashi, T., Kajiura-Kobayashi, H., Nagahama, Y., 2003. Induction of XY sex reversal by estrogen involves altered gene expression in a teleost, tilapia. Cytogenet. Genome Res. 101, 289-294.

Kobayashi, T., Matsuda, M., Kajiura-Kobayashi, H., Suzuki, A., Saito, N., Nakamoto, M., Shibata, N., Nagahama, Y., 2004. Two DM domain genes, DMY and DMRT1, involved in testicular differentiation and development in the medaka, Oryzias latipes. Dev. Dyn. 231, 518-526.

Kobayashi, T., Kajiura-Kobayashi, H., Guan, G., Nagahama, Y., 2008. Sexual dimorphic expression of DMRT1 and Sox9a during gonadal differentiation and hormone-induced sex reversal in the teleost fish Nile tilapia (Oreochromis niloticus). Dev. Dyn. 237, 297-306.

Kondo, M., Nanda, I., Hornung, U., Schmid, M., Schartl, M., 2004. Evolutionary origin of the medaka Y chromosome. Curr. Biol. 14, 1664-1669.

Luckenbach, J.A., Iliev, D.B., Goetz, F.W., Swanson, P., 2008. Identification of differentially expressed ovarian genes during primary and early secondary oocyte growth in coho salmon, 
Oncorhynchus kisutch. Reprod. Biol. Endocrinol. 6, 2.

McConnell, S.C., Restaino, A.C., de Jong, J.L.O., 2013. Multiple divergent haplotypes express completely distinct sets of class I MHC genes in zebrafish. Immunogenetics 66, 199-213.

Masuyama, H., Yamada, M., Kamei, Y., Fujiwara-Ishikawa, T., Todo, T., Nagahama, Y., 2012. Dmrt1 mutation causes a male-to-female sex reversal after the sex determination by Dmy in the medaka. Chromosome Res. 20, 163-176.

Matsuda, M., Nagahama, Y., Shinomiya, A., Sato, T., Matsuda, C., Kobayashi, T., Morrey, C.E., Shibata, N., Asakawa, S., Shimizu, N., Hori, H., Hamaguchi, S., Sakaizumi, M., 2002. DMY is a Y-specific DM-domain gene required for male development in the medaka fish. Nature 417, 559-563.

Matsuda, M., Sato, T., Toyazaki, Y., Nagahama, Y., Hamaguchi, S., Sakaizumi, M., 2003. Oryzias curvinotus has DMY, a gene that is required for male development in the medaka, O. latipes Zoolog. Sci. 20, 159-161.

Matsuda, M., Shinomiya, A, Kinoshita, M, Suzuki, A., Kobayashi, T., Paul-Prasanth, B., Lau, E.L., Hamaguchi, S., Sakaizumi, M., Nagahama, Y., 2007. DMY gene induces male development in genetically female (XX) medaka fish. Proc. Natl. Acad. Sci. USA 104, 3865-3870.

Myosho, T., Otake, H., Masuyama, H., Matsuda, M., Kuroki, Y., Fujiyama, A., Naruse, K., 
Hamaguchi, S., Sakaizumi, M., 2012. Tracing the emergence of a novel sex-determining gene in medaka, Oryzias luzonensis. Genetics 191, 163-170.

Nakamoto, M., Suzuki, A., Matsuda, M., Nagahama, Y., Shibata, N., 2005. Testicular type Sox 9 is not involved in sex determination but might be in the development of testicular structures in the medaka, Oryzias latipes. Biochem. Biophys. Res. Commun. 333, 729-736.

Nakamura, M., Kobayashi, T., Chang, X.T., Nagahama, Y., 1998. Gonadal sex differentiation in teleost fish. J. Exp. Zool. 281, 362-372.

Nanda, I., Kondo, M., Hornung, U., Asakawa, S., Winkler, C., Shimizu, A., Shan, Z., Haaf, T., Shimizu, N., Shima, A, Schmid, M., Schartl, M., 2002. A duplicated copy of DMRT1 in the sex-determining region of the Y chromosome of the medaka, Oryzias latipes. Proc. Natl. Acad. Sci. USA 99, 11778-11783.

Nanda, I., Shan, Z., Schartl, M., Burt, D.W., Koehler, M., Nothwang, H., Grützner, F., Paton, I.R., Windsor, D., Dunn, I., Engel, W., Staeheli, P., Mizuno, S., Haaf, T., Schmid, M., 1999. 300 million years of conserved synteny between chicken $\mathrm{Z}$ and human chromosome 9. Nat. Genet. 21, 258-259.

Nanda, I., Zend-Ajusch, E., Shan Z., Grützner, F., Schartl, M., Burt, D.W., Koehler, M., Fowler, V.M., Goodwin, G., Schneider, W.J., Mizuno, S., Dechant, G., Haaf, T., Schmid, M., 2000. Conserved synteny between the chicken $\mathrm{Z}$ sex chromosome and human chromosome 9 
includes the male regulatory gene DMRT1: a comparative (re)view on avian sex determination. Cytogenet. Cell Genet. 89, 67-78.

Niwa, H., Yamamura, K., Miyazaki, J., 1992. Efficient selection for high-expression transfectants with a novel eukaryotic vector. Gene 108, 193-200

Ottolenghi, C., Omari, S., Garcia-Ortiz, J.E., Uda, M., Crisponi, L., Forabosco, A., Pilia, G., Schlessinger, D., 2005. Foxl2 is required for commitment to ovary differentiation. Hum. Mol. Genet. 14, 2053-2062.

Pailhoux, E., Vigier, B., Chaffaux, S., Servel, N., Taourit, S., Furet, J.P., Fellous, M., Grosclaude, F., Cribiu, E.P., Cotinot, C., Vaiman, D., 2001. A 11.7-kb deletion triggers intersexuality and polledness in goats. Nat. Genet. 29, 453-458.

Pailhoux, E., Vigier, B., Vaiman, D., Servel, N., Chaffaux, S., Cribiu, E.P., Cotinot, C., 2002. Ontogenesis of female-to-male sex-reversal in XX polled goats. Dev. Dyn. 224, 39-50. Raymond, C.S., Kettlewell, J.R., Hirsch, B., Bardwell, V.J., Zarkower, D., 1999. Expression of Dmrt1 in the genital ridge of mouse and chicken embryos suggests a role in vertebrate sexual development. Dev. Biol. 215, 208-220.

Raymond, C.S., Parker, E.D., Kettlewell, J.R., Brown, L.G., Page, D.C., Kusz, K., Jaruzelska, J., Reinberg, Y., Flejter, W.L., Bardwell, V.J., Hirsch, B., Zarkower, D., 1999. A region of human chromosome $9 \mathrm{p}$ required for testis development contains two genes related to known 
sexual regulators. Hum. Mol. Genet. 8, 989-996.

Raymond, C.S., Shamu, C.E., Shen, M.M., Seifert, K.J., Hirsch, B., Hodgkin, J., Zarkower, D., 1998. Evidence for evolutionary conservation of sex-determining genes. Nature 391, 691-695.

Sadler, J.E., 1998. Biochemistry and genetics of von willebrand factor. Ann. Rev. Biochem. 67, 395-424.

Sawatari, E., Shikina, S., Takeuchi, T., Yoshizaki, G., 2007. A novel transforming growth factor-beta superfamily member expressed in gonadal somatic cells enhances primordial germ cell and spermatogonial proliferation in rainbow trout (Oncorhynchus mykiss). Dev. Biol. 30, 266-275.

155 Shibata, K., Takase, M., Nakamura, M., 2002. The Dmrt1 expression in sex-reversed gonads of amphibians. Gen. Comp. Endocrinol. 127, 232-241.

Shibata, Y., Paul-Prasanth, B., Suzuki, A., Usami, T, Nakamoto, M., Matsuda, M., Nagahama, Y., 2010. Expression of gonadal soma derived factor (GSDF) is spatially and temporally correlated with early testicular differentiation in medaka. Gene Expr. Patterns 10, 283-289.

160 Smith, C.A., McClive, P.J., Western, P.S., Reed, K.J., Sinclair, A.H., 1999. Conservation of a sex-determining gene. Nature 402, 601-602.

Smith, C.A., Katz, M., Sinclair, A.H., 2003. DMRT1 is upregulated in the gonads during 
female-to-male sex reversal in ZW chicken embryos. Biol. Reprod. 68, 560-570.

Smith, C.A., Roeszler, K.N., Ohnesorg, T., Cummins, D.M., Farlie, P.G., Doran, T.J., Sinclair, A.H., 2009. The avian Z-linked gene DMRT1 is required for male sex determination in the chicken. Nature 461, 267-271.

Takasawa, K., Kashimada, K., Pelosi, E., Takagi, M., Morio, T., Asahara, H., Schlessinger, D., Mizutani, S., Koopman, P., 2014. FOXL2 transcriptionally represses Sf1 expression by antagonizing WT1 during ovarian development in mice. FASEB J. 28, 2020-2028.

Takehana, Y., Matsuda, M., Myosho, T., Suster, M.L., Kawakami, K., Shin-I, T., Kohara, Y., Kuroki, Y., Toyoda, A., Fujiyama, A., Hamaguchi, S., Sakaizumi, M., Naruse, K., 2014. Co-option of Sox 3 as the male-determining factor on the Y chromosome in the fish Oryzias dancena. Nature Commun. 5, 4157.

Thermes, V., Grabher, C., Ristoratore, F., Bourrat, F., Choulika, A., Wittbrodt, J., Joly, J., 2002. I-SceI meganuclease mediates highly efficient transgenesis in fish. Mech. Dev. 118, 91-98.

Veitia, R.A., Salas-Cortes, L., Ottolenghi, C., Pailhoux, E., Cotinot, C., Fellous, M., 2001. Testis determination in mammals: more questions than answers. Mol. Cell. Endocrinol. 179, 3-16.

Vidal, V.P., Chaboissier, M.C., de Rooij, D.G., Schedl, A., 2001. Sox9 induces testis development in XX transgenic mice. Nat. Genet. 28, 216-217. 
regulatory putsches and ephemeral dictators. Sex. Dev. 1, 85-99.

Wang, D.S., Kobayashi, T., Zhou, L.Y., Paul-Prasanth, B., Ijiri, S., Sakai, F., Okubo, K., Morohashi, K., Nagahama, Y., 2007. Foxl2 up-regulates aromatase gene transcription in a female-specific manner by binding to the promoter as well as interacting with ad4 binding protein/steroidogenic factor 1. Mol. Endocrinol. 21, 712-725.

Yan, H., Ijiri, S., Wu, Q., Kobayashi, T., Li, S., Nakaseko, T., Adachi, S., Nagahama, Y., 2012. Expression patterns of gonadotropin hormones and their receptors during early sexual differentiation in Nile tilapia Oreochromis niloticus. Biol. Reprod. 87, 116.

Yano, A., Guyomard, R., Nicol, B., Jouanno, E., Quillet, E., Klopp, C., Cabau, C., Bouchez, O., Fostier, A., Guiguen, Y., 2012. An immune-related gene evolved into the master sex-determining gene in rainbow trout, Oncorhynchus mykiss. Curr. Biol. 22, 1423-1428.

Yoshimoto, S., Okada, E., Umemoto, H., Tamura, K., Uno, Y., Nishida-Umehara, C., Matsuda, Y., Takamatsu, N., Shiba, T., Ito, M., 2008. A W-linked DM-domain gene, DM-W, participates in primary ovary development in Xenopus laevis. Proc. Natl. Acad. Sci. USA 105, 2469-2474.

Zhou, L.Y., Wang, D.S., Kobayashi, T., Yano, A., Paul-Prasanth, B., Suzuki, A., Sakai, F., Nagahama, Y., 2007. A novel type of P450c17 lacking the lyase activity is responsible for C21-steroid biosynthesis in the fish ovary and head kidney. Endocrinology 148, 4282-4291. 
Fig. 1. Microarray screening for identifying predominantly expressed genes in either XX or

\section{XY gonads}

A. Representative scatter plots of cDNA microarray analysis. XY gonads at $5 \mathrm{dph}$ (labeled with Au particles) and XX gonads at 5 dph (labeled with Ag particles) were labeled and hybridized to

conducted (b). B. Twelve genes were identified by quantitative RT-PCR from 176 genes selected by the microarray screening. The levels of mRNA encoding each gene were measured using total RNA extracted from XX and XY gonads at 5, 6, and $7 \mathrm{dph}(\mathrm{c}-\mathrm{n})$.

\section{Fig. 2. Alignment of TGF-beta domain amino-acid sequences}

Multiple alignment of TGF-beta domain sequences of teleost GSDFs, human TGF-beta family members, and human CG beta. Conserved amino acids of the cystine knot are boxed and shown below the alignment.

\section{Fig. 3. Phylogenetic tree of the amino acid sequences of \#9475 and the transforming growth}

\section{factor-beta superfamily}

The phylogenetic tree for \#9475/gsdf, the gonadal soma-derived factor (GSDF) homolog of 
teleosts, and the transforming growth factor (TGF)-beta superfamily was generated using the neighbor-joining method. Human CG beta was defined as the root. The percentages of replicate 220 trees in which the associated taxa clustered together in the bootstrap test (1,000 replicates) are shown next to the branches. Scale bars indicate substitutions per site.

\section{Fig. 4. Tissue distribution of \#9475/gsdf mRNA by RT-PCR}

A. The upper panel displays the RT-PCR results for \#9475/gsdf mRNA obtained from various

225 tissues of adult female and male tilapia. The \#9475/gsdf mRNA was expressed only in gonadal tissues. The expression was strong in testes and weak in ovaries. The lower panel shows the results for $\beta$-actin (internal control). B. The mRNA levels of $\# 9475 / g s d f$ in adult ovary or testis are shown. The levels of \#9475/gsdf mRNA were measured by quantitative one-step RT-PCR using total RNA extracted from adult ovaries and testes. The double asterisk indicates significant 230 difference of $p<0.01$.

Fig. 5. \#9475/gsdf gene expression during gonadal differentiation determined by quantitative one-step real-time RT-PCR analysis

A. Changes in mRNA levels of the \#9475/gsdf gene were measured in XX and XY gonads

235 during gonadal development at 5, 6, 7, 10, 15, 25, 35 and 70 days post-hatching (dph). Closed 
circles represent the means of XX gonads, whereas open squares represent those of XY gonads.

Total RNA was extracted from pooled samples including 30-50 gonads on each sampling day.

Each reaction was conducted using $10 \mathrm{ng}$ of total RNA. B. The mRNA levels of \#9475/gsdf and dmrtl in $\mathrm{XX}$ or $\mathrm{XY}$ undifferentiated gonads from 5 to $6 \mathrm{dph}$ are shown. The numerals beside

240 each column and point indicate the number of pooled samples $(n)$ used for measurement. The asterisk and double asterisk indicate significant differences of $p<0.05$ and $p<0.01$, respectively.

Fig. 6. Sexual dimorphism of \#9475/gsdf mRNA expression observed in whole-mount in situ hybridization

Localization of \#9475/gsdf $m R N A$ was examined by whole-mount in situ hybridization. A-D:

XY gonads. E-H: XX gonads. Panels B, D, F, and H are high-magnification images of panels A, C, E, and G, respectively. A, B, E, F: gonads at 10 days post-hatching. C, D, G, H: gonads at 20 days post-hatching. Scale bars for A, C, E and G, $50 \mu \mathrm{m}$; Scale bars for B, D, F and H, $25 \mu \mathrm{m}$.

Fig. 7. Localization of \#9475/gsdf mRNA during gonadal differentiation observed by in situ

\section{hybridization}

A-E, K-M: XY gonads. F-J, N-P: XX gonads. A, F: Gonads at 3 days post-hatching (dph). B, 
G: Gonads at 5 dph. C, H: 7 dph. D, I: 10 dph. E, J: 20 dph. K, N: 40 dph. L, O: 70 dph. M:

255 Adult testis. P: Adult ovary. Small arrows, Epithelial cells of (intratesticular) efferent duct. Large arrows, (Intratesticular) efferent duct. Arrowheads, Type A spermatogonium. The dotted line in panel D indicates the outline of the germ cell. Scale bars for A-J, $10 \mu \mathrm{m}$; scale bars for K-P, 20 $\mu \mathrm{m}$. Fig. 8. Localization of \#9475/Gsdf protein in undifferentiated gonads and adult testis

A. Immunoblot analysis of lysate prepared from adult testis (a) and ovary (b). Immunoblot analysis of incubation media of HEK293 cells transfected with the expression vector harboring the ORF of \#9475/Gsdf at 1 or 2 days after transfection (c1 and c2, respectively). B. Immunolocalization of \#9475/Gsdf in XY (d) or XX (e) undifferentiated gonads at $7 \mathrm{dph}$. The

265 dotted lines indicate the outline of germ cells. C. Adult testis. (f): hematoxylin-eosin staining; inset, high magnification of enclosed box. (g): Immunolocalization of \#9475/Gsdf in the adjacent section used in Panel $\mathrm{f}$ (ALP/NBT and BCIP staining); inset, high magnification of the area indicated by small arrow. The small arrow indicates epithelial cells of the intratesticular efferent duct. (h): High magnification of enclosed dotted box indicated in panel g (HRP/DAB staining).

270 The dotted line indicates the outline of a type-A spermatogonia. Scale bars for $\mathrm{d}, \mathrm{e}, \mathrm{h}$, and insets $\mathrm{f}$ and $\mathrm{g}, 10 \mu \mathrm{m}$; scale bars for $\mathrm{f}$ and $\mathrm{g}, 100 \mu \mathrm{m}$. 


\section{Fig. 9. Overexpression of \#9475/gsdf in XX tilapia}

\#9475/gsdf cDNA was introduced into XX fertilized eggs at the one-cell stage. A: Control XX

275 gonad at 11 months after injection. Gonads immunostained by the cyp19a1a antibody.

Cyp19a1a-positive cells were localized in thecal cells. B: Gonads from XX transgenic fish at 11 months after injection; inset, expression of GFP of the gonad in a dark field. XX fertilized eggs were injected CMV promoter-derived expression vector inserted \#9475/gsdf open reading frame. C: Gonads from control XX fish at 3 months. D: Gonads from XX transgenic fish at 3 months

280 after injection. XX fertilized eggs were injected AG promoter-derived expression vector inserted \#9475/gsdf open reading frame alone with I-SceI meganuclease. I-SceI meganuclease recognition sequence was introduced after the polyadenylation signal of the vector itself. Scale bars for A-D represent $20 \mu \mathrm{m}$. Scale bar for inset in panel B indicates $2 \mathrm{~mm}$.

285 Supplemental Material 2. In situ hybridization using \#9475/gsdf sense probe (A) or anti-sense probe (B) in XY gonads at 8 days post hatching. Dtection of \#9475/gsdf mRNA by in situ hybridization in XY (C) and XX (D) tilapia gonads at 4 days post hatching. Arrow indicates \#9475/gsdf mRNA positive cell. Scale bars represent $10 \mu \mathrm{m}$. 
tilapia_9475_gsdf

Rainbow_trout_GSDF

Rainbow trout_GSDF2

Medaka_G_SDF

Zebrafish GSDF

Stickleback GSDF

Chub_mackerel_GSDF

Fugu GSDF

human_BMP2

human inhibin bA

human_Nodal

human GDF1

human_TGEb1

human $\mathrm{AMH}$

human_GDNF

human_CG beta

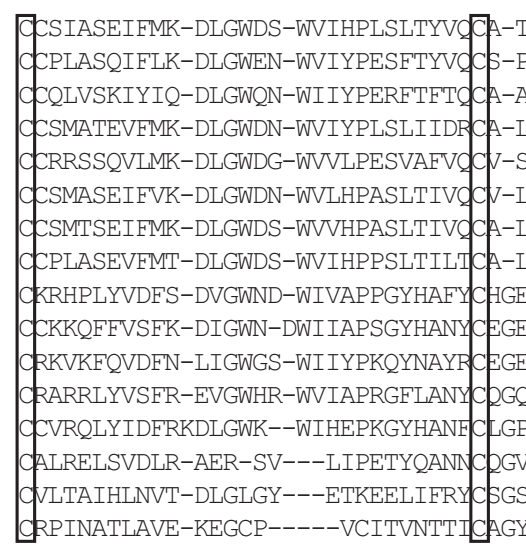

---NSAMTTVQCPSSQV-----NVQDAN--TQDQVP-------Cq
-KSRLDLSPSRCPSHAP-----PAQDT----PSQMP------
-TTQLNPAGQQCGAHLP-----SQD-S----TPEVS------

--RPTSOEEVP-IVYMDGSSAIVMSS--MOLTRSICEC --QTTSTEHVP-FLYMDEFSTLTIPS--VQLTRACGP --KPASQHLVP-VLYLDEFNTLIISS--VYLTRDC --KPTSLEIVP-IVEMDETSTIVISS--VQLARQCAC --KPTAHHIVP-FVYMDA-SGLVLST--VRLPRDCAC --VPIAQEMVP-VVYLDELSTLVISS--VQLTRSd d A --QPTSQEMVP-IVYVDQESTLVISS--VQLTRSCAC -QLTSMKMVP-IVYVDQFATLTMAS--VQLPSNCAC --VPTELSAIS-MLYLDENEKVVLKNYQDMVVEQCAC -VPTKLRPMS-MLYYDDGQNI IKKDIQNMIVEA CAC -APVKTKPLS-MLYVDN-GRVLLDHHKDMIVEECAC -VPARLSPIS-VLFFDNSDNVVLRQYEDMVVDECAC -VPQALEPLP-IVYYVGR-KPKVEQLSNMIVRSCAC -VPTAYAGKL-LISLSEE-RISAHHVPNMVATECAC -RPIAFDDD--LSFLDD--NLVYHILRKHSAKA CAC TYRDVRFESIR-LPGCPRGVNPVVSY---AVAL,SCDd

Fig. 2 



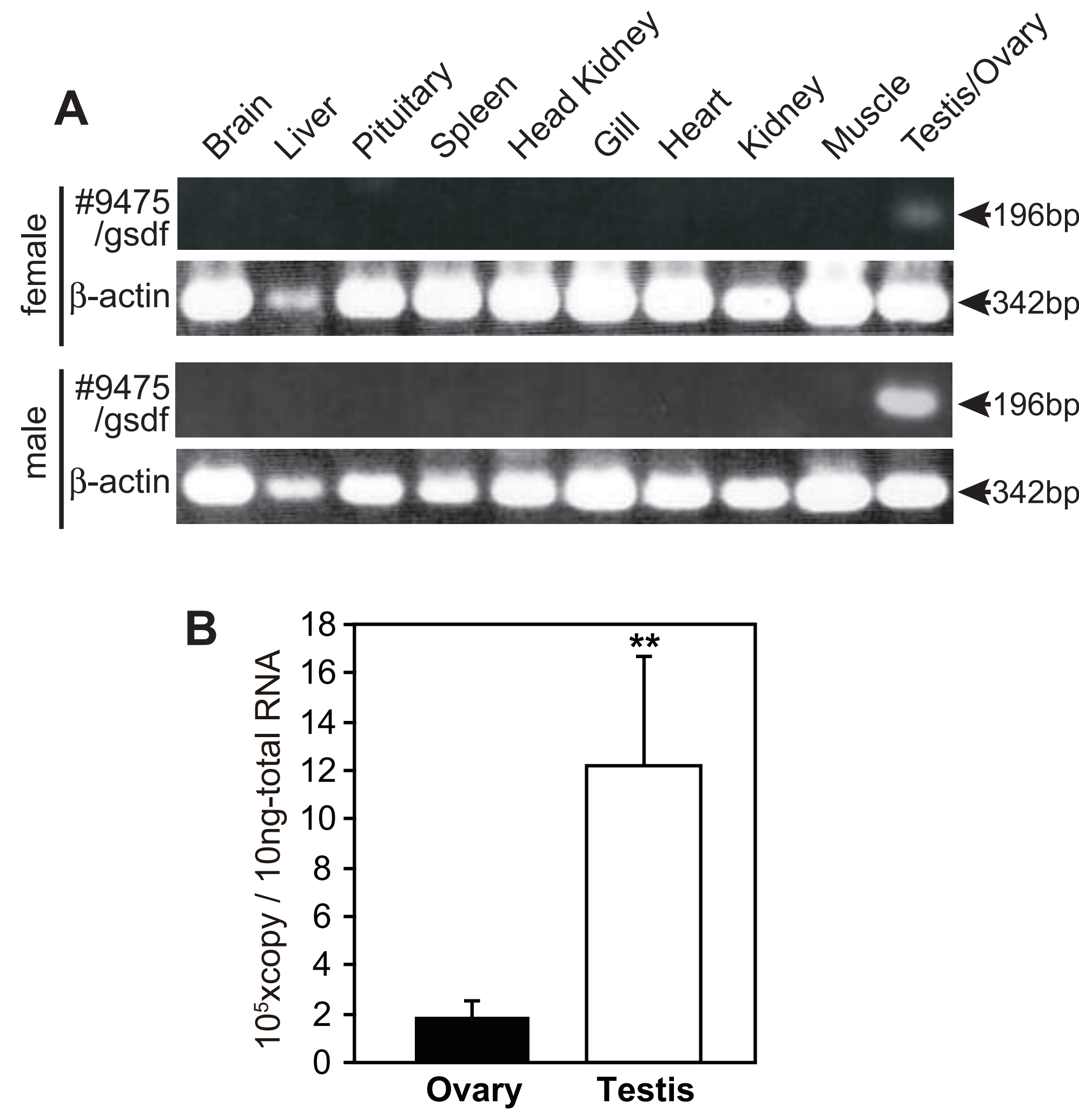

Fig. 4 
B
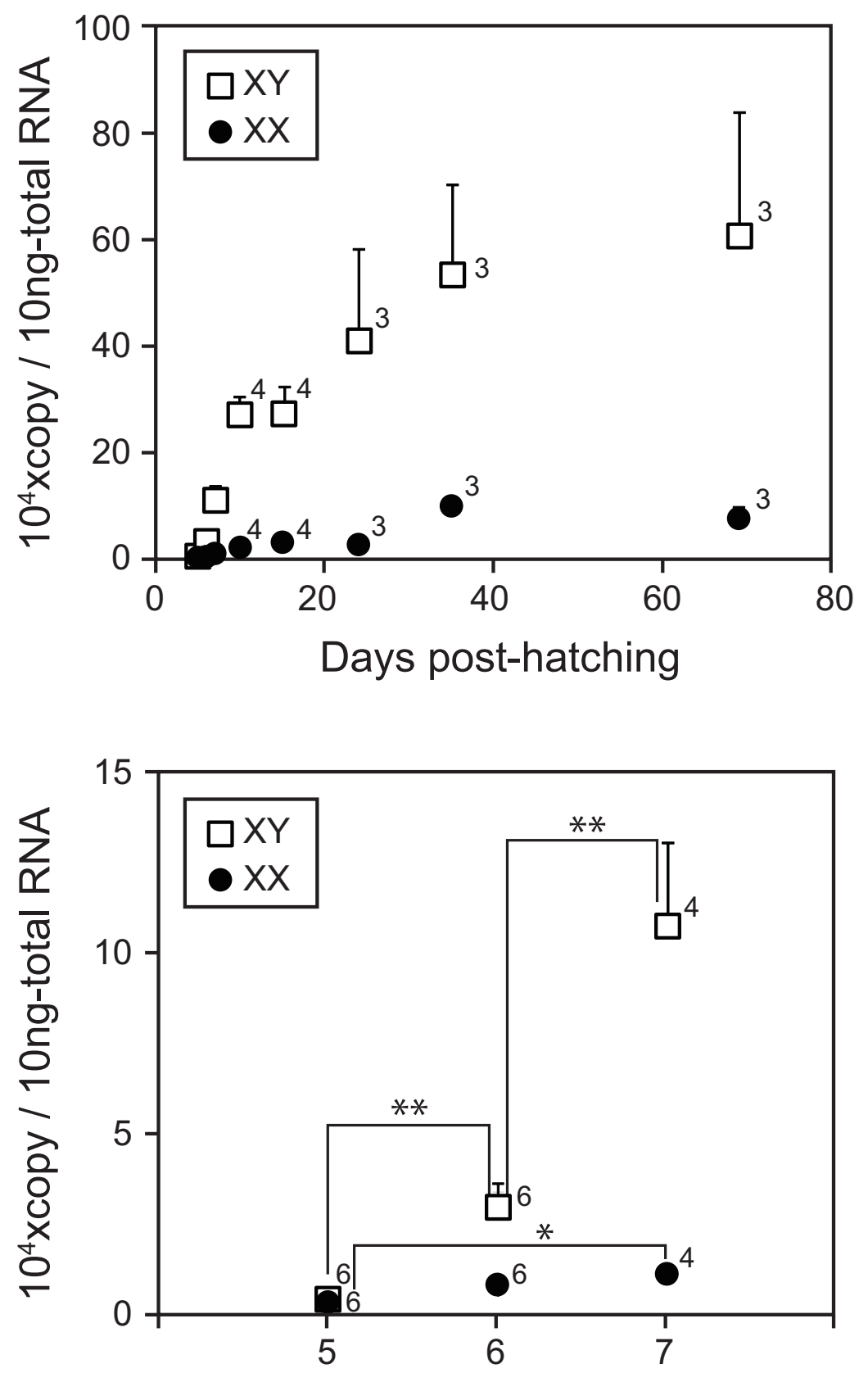

Days post-hatching

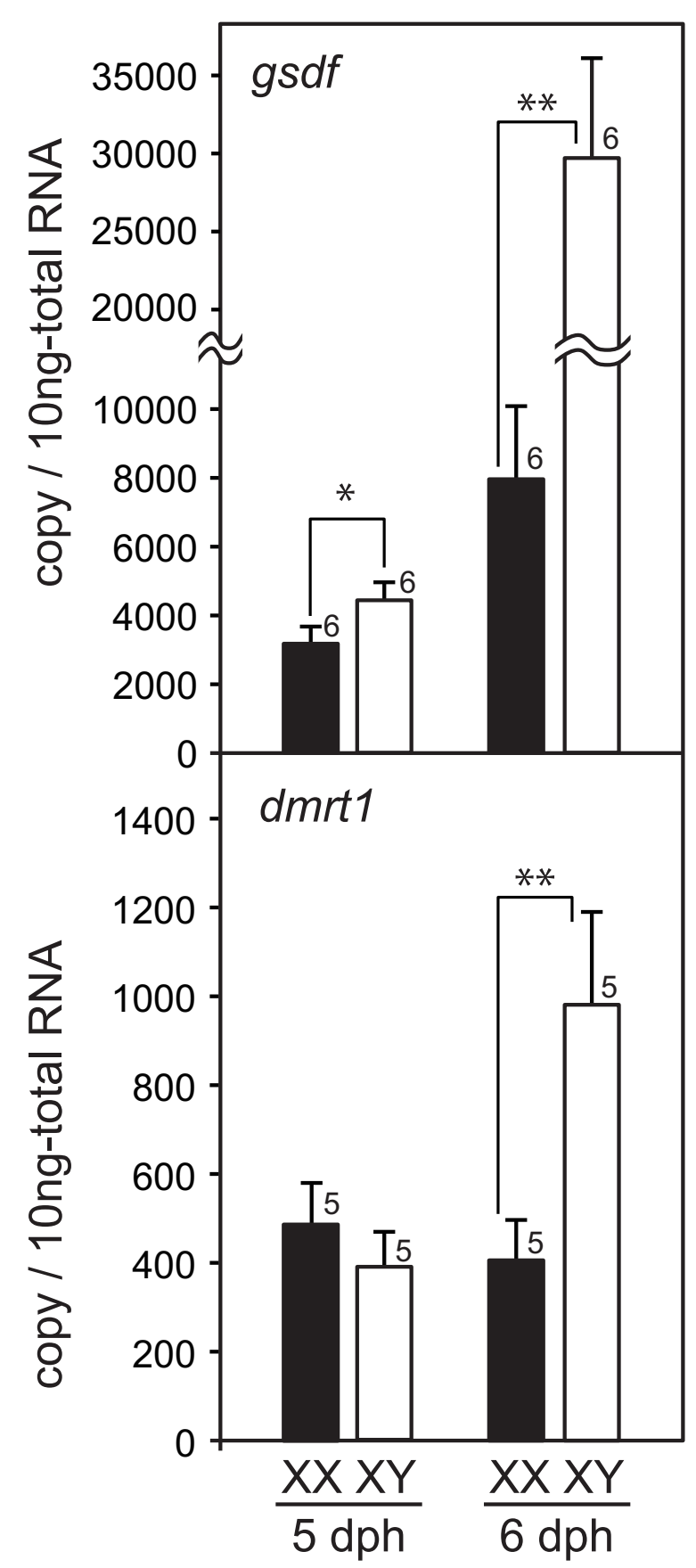

Fig.5 
$X Y$ gonads

흥

A

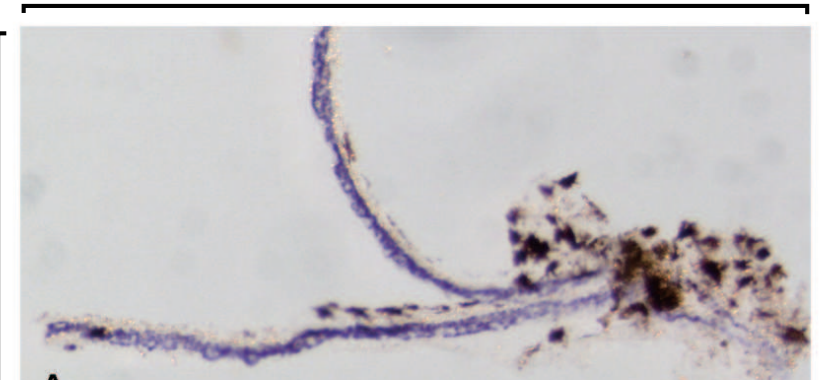

$\therefore$ E
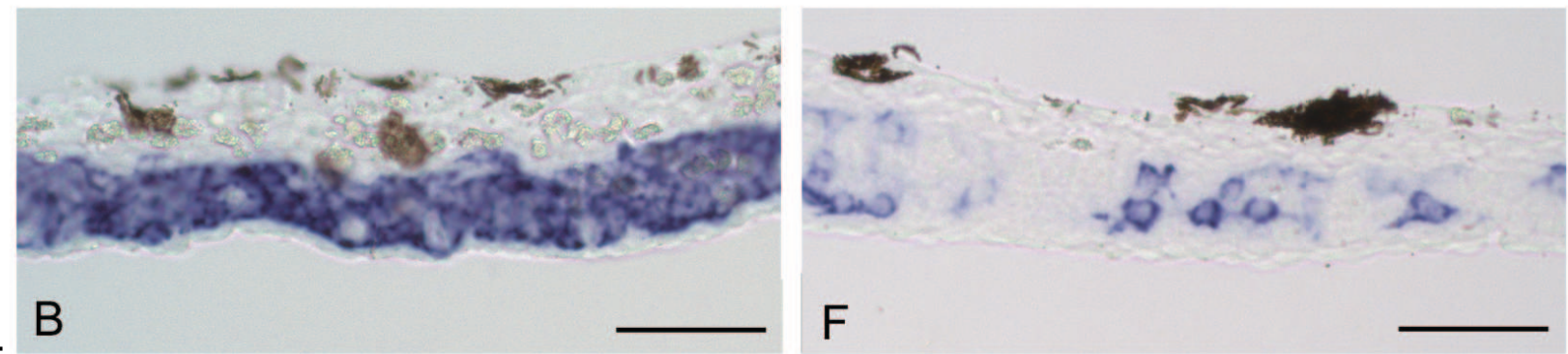

등

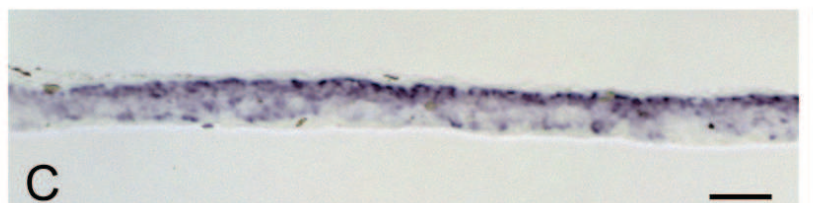

C
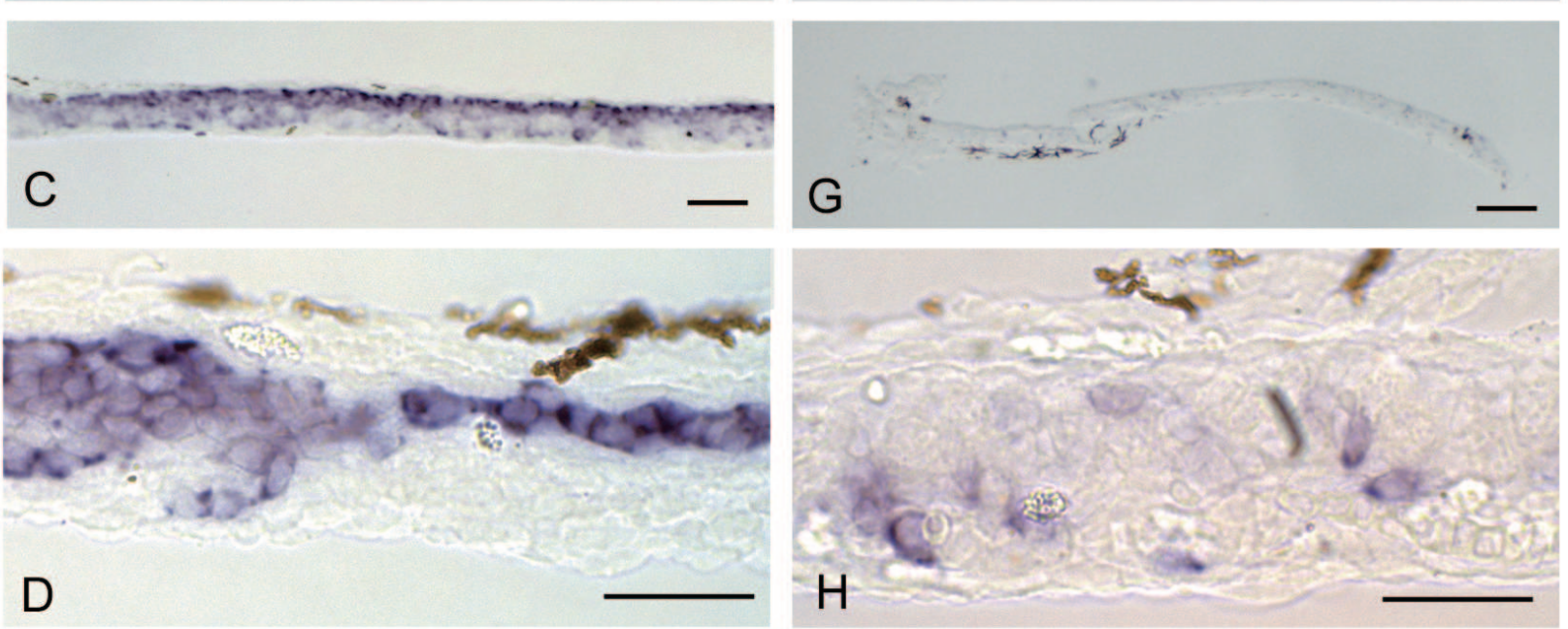

Fig. 6 


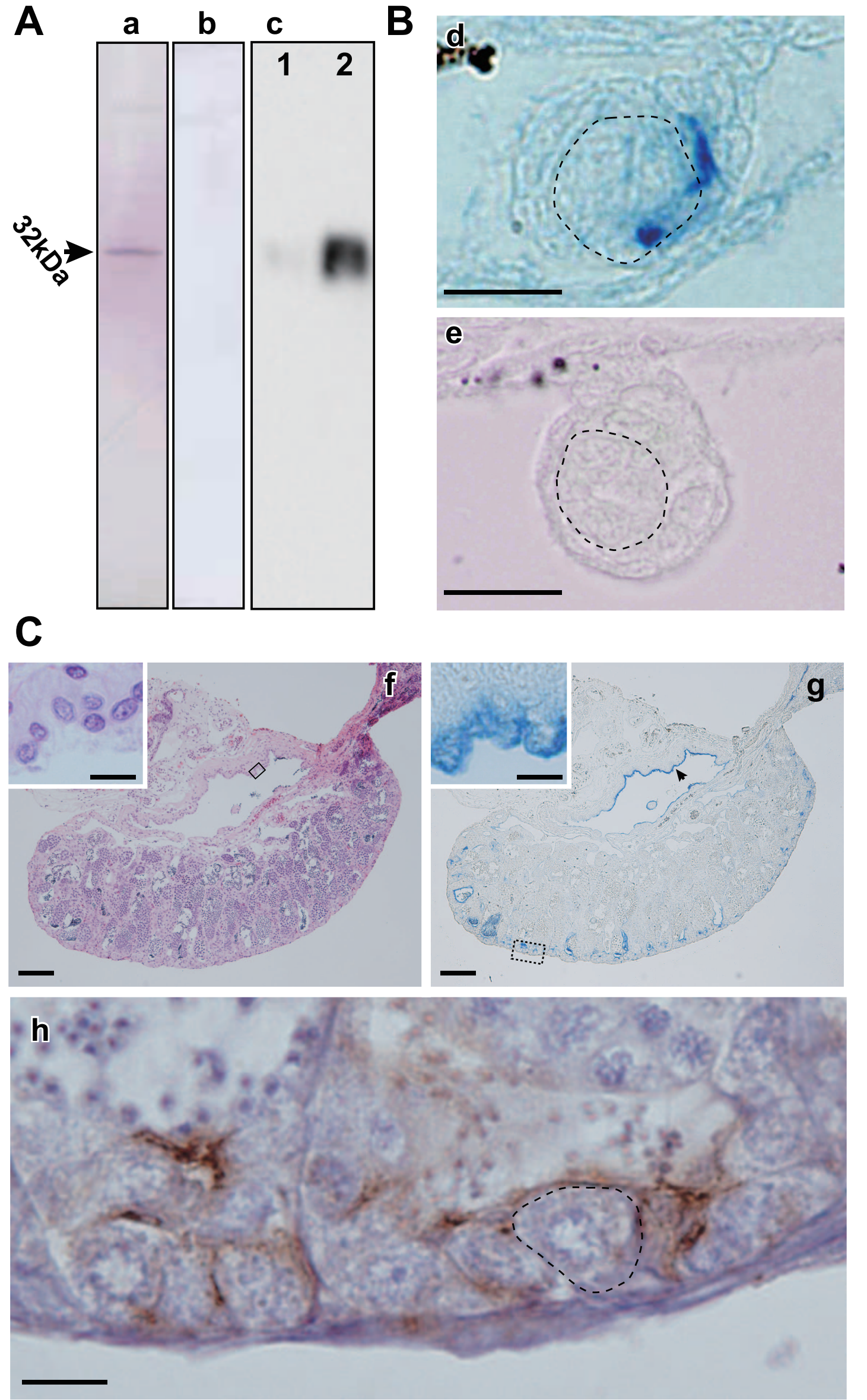

Fig. 8 
